\title{
Analysis of metabolic syndrome factors to determine contributions to pathogenesis of mammary gland disease in Japanese women- Case-control study based on health screening results
}

Tadayuki lida ( $\square$ iida@pu-hiroshima.ac.jp )

Prefectural University of Hiroshima https://orcid.org/0000-0003-4934-3576

\section{Sakika Sumida}

Yoshida General Hospital

\section{Yoshikawa Masao}

Preventive Medicine Promotion Research Center

\section{Nagaoka Kaoru}

Preventive Medicine Promotion Research Center

Research article

Keywords: mammary gland disease, metabolic syndrome factors, breast cancer screening

Posted Date: May 29th, 2020

DOI: https://doi.org/10.21203/rs.3.rs-28907/v1

License: (c) (i) This work is licensed under a Creative Commons Attribution 4.0 International License. Read Full License 


\section{Abstract}

Background: Recently, the relationship between obesity and breast cancer has been clarified, and findings obtained in a study that used body mass index (BMI) suggested that its presence might increase the risk for development of that disease. However, the association between metabolic syndrome caused by obesity and development of mammary gland disease has not been elucidated in a longitudinal manner. In the present case-control study, that association was examined.

Methods: Two hundred sixty-five women who underwent breast cancer screening with mammography and measurements of metabolic syndrome factors, including waist circumference, blood glucose, and triglycerides, HDL-cholesterol levels, and systolic and diastolic blood pressure, twice within a 2-year period at the Disease Prevention Promotion and Research Center of the Dai-ikai Medical Corporation were enrolled. To determine the presence of mammary gland disease, 2 expert physicians interpreted radiogram findings, with category 3 or higher shown by mammography considered to indicate an abnormality.

Results and Discussion: Waist circumference at the initial measurement was shown to be significantly associated (odds ratio $=1.036, p=0.045$ ) as a risk factor for onset of mammary gland disease. During the 2 -year examination period, changes in systolic blood pressure (odds ratio $=1.020, p=0.085$ ) and diastolic pressure (odds ratio $=1.040, p=0.065$ ) showed a marginally significant association. As for protective factors, HDL-cholesterol level (odds ratio $=0.982, p=0.064$ ) at the initial examination was confirmed to have a marginally significant relationship. We concluded that waist circumference and 2-year changes in systolic and diastolic blood pressure are risk factors for mammary gland disease, while HDL-cholesterol level is a protective factor.

\section{Introduction}

According to the National Cancer Center of Japan, the number of breast cancer cases in 2016 was 94,848 , while the number of deaths showed an increasing tendency in 2017 to 14,285. Although the Ministry of Health, Labor and Welfare of Japan has been conducting activities for raising awareness of breast cancer screening, the consultation rate has remained low. In recent years, the association between breast cancer and obesity has been clarified, with the westernization of dietary habits considered to be an important cause [1-5]. Obesity is a state of excessive fatty tissue caused by hypertrophy and leads to an increase in that tissue. The increased fatty tissue produces estrogen via an androgenic hormone (androgen) secreted from the adrenal cortex. Thus, it is considered that hypertrophy and increased fatty tissue enhance exposure to estrogen, indicating a close relationship with onset of breast cancer. Meanwhile, fatty tissue induces production and secretion of various adipocytokines. It has also been reported that hypertrophy and increased fatty tissue cause a non-uniform secretion of adipocytokines, which have effects on mammary gland tissue that can lead to development of breast cancer. Such uneven levels of secretion also elevate insulin sensitivity, facilitate glucose metabolism, and suppress blood pressure increase by a vasodilating effect. As a result, hypertrophy and increased fatty tissue 
induce abnormal glucose metabolism and hypertension, advancing metabolic syndrome [6, 7]. Although the association of obesity, namely expanded waist circumference, and body mass index (BMI) with onset of breast cancer is predictable, the causal relationship between metabolic syndrome factors including waist circumference and risk for breast cancer development has yet to be elucidated.

Previous studies of breast cancer that utilized BMI considering the presence of excess fatty tissue as 'obesity'. Each of 4 case control studies thus far presented reported that an increase in BMI was significantly associated with increased risk for breast cancer. However, those cross-sectional studies examined the association with $\mathrm{BMI}$ at the time of breast cancer onset and no longitudinal studies regarding $\mathrm{BMI}$ as an excessive state of fatty tissue have been presented.

Based on those previous studies, it is speculated that there might be an association between metabolic syndrome in regard relating to fatty tissue hypertrophy and increase, and increased risk for breast cancer development. However, few studies have examined the longitudinal association between biochemical factors related to metabolic syndrome and risk for breast cancer onset.

For the purpose of increasing awareness of the importance of early detection of breast cancer for early treatment and reducing associated mortality, we performed a longitudinal examination of the association of metabolic syndrome factors, including waist circumference, levels of glucose, blood pressure, triglycerides, and HDL-cholesterol in blood, and blood pressure, with development of mammary gland diseases including breast cancer using data obtained in routine health checkup examinations.

\section{Subjects And Methods}

\section{Subjects}

The records of 314 women who underwent breast cancer screening examinations with mammography and blood tests, and also had body weight and height, and BMI values recorded, were analyzed. Of those, 89 participated in a screening examination twice, once in 2010 (initial) and again in 2012 (2 years later), and another 225 women underwent those in 2011 (initial) and 2013 ( 2 years later). Of 301 women classified as other than abnormality detected at the initial screening and who completed a questionnaire, 80 had an abnormality detected at the second examination 2 years later and were designated as the case group. Furthermore, 221 women classified as other than abnormality detected were matched with the case group in terms of age ( \pm 2 years) and BMI $\left( \pm 2 \mathrm{~kg} / \mathrm{m}^{2}\right)$ and designated as the control group. Later, 36 in the control group were excluded because of missing test data or outside of the matching values, thus the total number of subjects in the control group was 185 (Fig. 1).

For determining abnormal status, we used the 5-category assessment of final malignancy shown in the Mammography Screening Guidelines based on the Breast Imaging Reporting and Data System (BI-RADS) prepared by the American College of Radiology (ACR). According to those criteria, categories 3 to 5 are classified as requiring further detailed examinations. In the present case-control study, subjects classified 
as category 3 or higher for mammary gland disease including breast cancer were regarded as having abnormal findings and used as the case group. This study recieved approval from the Ethics Committee of Hiroshima Koseiren Yoshida General Hospital (approval no. 201607) and was performed in accordance with the Declaration of Helsinki.

\section{Examination Items}

In the period from 2010 to 2013, all subjects were examined twice (initial and 2 years later) for physical characteristics as well as blood testing, with those items used as metabolic syndrome factors, and also underwent breast cancer screening.

\section{Physical characteristics}

For the physical characteristics, age, height, body weight, and waist circumference were determined. BMI was calculated on the basis of height and weight. For blood pressure, systolic and diastolic pressure, known to be major risk factors for circulatory disease, were determined.

\section{Metabolic syndrome factors}

Among the metabolic syndrome factors examined, blood testing for glucose, triglyceride, and HDLcholesterol levels was performed as a biochemical examination with a HITACHI DM-JACS device. For the reagents, Determiner L GLU HK was used for blood glucose, Determiner L TG for triglycerides, and Metabolead HDL-C for HDL-cholesterol measurements. All reagents were provided by Kyowa Medex Co. Ltd. (presently, Hitachi Chemical Diagnostics Systems Co., Ltd.).

\section{Breast cancer screening}

For breast cancer screening, a MGU-100D mammographic device (Toshiba Medical Systems Corporation (presently, Canon Medical Systems Corporation) was used, which met the criteria of the Japan Radiological Society. Mammography examinations were conducted at a certified facility. That facility has been accredited by the Japan Central Organization on Quality Assurance for Breast Cancer Screening (specified nonprofit organization) and the screening criteria were fulfilled on the basis of evaluations of mammography equipment, actual radiograms, and radiation dose for the purpose of enhancing and maintaining screening precision. For breast cancer screening, 2 qualified physicians with experience with mammogram interpretation (B1) certified by the Japan Central Organization on Quality Assurance of Breast Cancer Screening were in charge of the examinations. Two radiogram interpretations, first and second, were used for grading. Subjects classified as category 1 or 2 in the mammography results obtained 2 years after the initial screening were considered as other than abnormality detected, while those classified as category 3 or higher were considered to be abnormality detected related to onset of mammary gland disease.

\section{Statistical analysis}


Age, physical characteristics, and metabolic syndrome factors, including waist circumference, glucose, triglyceride, and HDL-cholesterol level, and systolic and diastolic blood pressure were recorded, and the normality of the initial test values was confirmed by use of a histogram and Kolmogorov-Smirnov test results $(p>0.05)$. Values from the initial measurements were subtracted from those obtained 2 years later for determining changes, with normality tested and confirmed in the same manner $(p>0.05)$. The mean and standard deviation were calculated for each test item. Furthermore, age, height, weight, and waist circumference, blood glucose, triglyceride, and HDL-cholesterol levels, and diastolic and systolic blood pressure were compared between included and excluded subjects using Student's t test.

Results obtained in the breast cancer screening test were used as dependent variables for examining the effects of risk factors with binominal logistic regression analysis. Before selecting the explanatory variables, the correlations of waist circumference, glucose, triglyceride, and HDL-cholesterol blood levels, and systolic and diastolic pressure determined at the initial measurement were examined using Pearson's correlation coefficient, with a strong correlation between systolic and diastolic blood pressure noted $(r=$ $0.806, p<0.001)$. Accordingly, in Model 1, waist circumference, glucose, triglyceride, HDL-cholesterol, and systolic blood pressure were used as explanatory variables. In Model 2, systolic pressure was replaced with diastolic blood pressure. For both Model 1 and 2, the effect of age was taken into consideration by using that at the initial screening as a regulating factor. Furthermore, for changes in waist circumference, blood glucose, triglyceride, and HDL-cholesterol levels, and systolic and diastolic pressure, the correlation of each variable was examined using Pearson's correlation coefficient. As a result, a strong correlation between changes in systolic and diastolic blood pressure was demonstrated $(r=0.635, p<0.001)$. In Model 3, changes in waist circumference, blood glucose, triglyceride, HDL-cholesterol, and systolic pressure were used as explanatory variables. By taking into consideration the effects of those at the initial measurement, each was used as a regulator factor. In Model 4, change in systolic pressure was replaced with diastolic pressure, while the other explanatory and regulator factors were the same as in Model 3. For all of these tests, a risk ratio of $5 \%$ or lower was considered to indicate statistical significance. For statistical analysis, SPSS 25.0J (KBM Japan, Tokyo) was used. The level of significance was set at $p<0.05$.

\section{Results}

Table 1 shows physical characteristics and biochemical test results as metabolic syndrome factors of subjects included and excluded from analysis conducted in the period from 2010 to 2013. There were no significant differences between the 265 subjects included and 36 excluded in regard to height, weight, $\mathrm{BMI}$, and waist circumference, glucose, triglyceride, HDL-cholesterol in blood, and diastolic blood pressure, whereas significant differences were confirmed for age and systolic blood pressure. In the subjects classified as other than abnormality detected, systolic pressure was significantly higher at the second as compared to the initial measurement. Comparisons of the examined metabolic syndrome factors between the initial measurements and those obtained 2 years later are shown in Table 2. In the group with an abnormality detected, the HDL-cholesterol level was significantly higher at the second 
measurement. In all subjects, waist circumference was significantly higher and systolic blood pressure significantly lower at the second measurement.

Table1. Physical characteristics and metabolic syndrome factor measurements in subjects and those excluded from analysis

\begin{tabular}{|c|c|c|c|c|c|c|c|}
\hline & \multicolumn{3}{|c|}{ Subjects } & \multicolumn{4}{|c|}{ Excluded (including lack of data) } \\
\hline & $\mathrm{n}$ & mean SD & $\min -\max$ & $\mathrm{n}$ & mean SD & $\min -\max$ & $\mathrm{p}$ value \\
\hline Age (y) & 265 & $47.8(8.0)$ & $35.0-78.0$ & 36 & $56.5(11.6)$ & $38.0-77.0$ & $<0.001$ \\
\hline Height $(\mathrm{cm})$ & 265 & $158.6(5.3)$ & $144.1-174.0$ & 22 & $156.5(5.5)$ & $147.2-167.7$ & 0.071 \\
\hline Body weight $(\mathrm{kg})$ & 265 & $53.2(8.2)$ & $40.1-108.3$ & 22 & $53.1(6.2)$ & $40.6-64.7$ & 0.980 \\
\hline Waist circumference $(\mathrm{cm})$ & 265 & $76.9(8.9)$ & $60.0-122.5$ & 20 & $80.3(8.9)$ & $64.5-95.8$ & 0.107 \\
\hline $\operatorname{BMI}\left(\mathrm{kg} / \mathrm{m}^{2}\right)$ & 265 & $21.2(3.2)$ & $16.2-45.1$ & 22 & $21.8(2.9)$ & $16.6-28.9$ & 0.393 \\
\hline Blood glucose (mg/dl) & 265 & $90.0(11.0)$ & $66.0-171.0$ & 7 & $86.7(5.8)$ & $79.0-92.0$ & 0.430 \\
\hline Triglycerides (mg/dl) & 265 & $80.6(48.5)$ & $27.0-428.0$ & 22 & $82.0(38.7)$ & $40.0-213.0$ & 0.897 \\
\hline HDL-cholesterol (mg/dl) & 265 & $76.8(16.0)$ & $33.0-130.0$ & 22 & $79.2(11.5)$ & $56.0-97.0$ & 0.493 \\
\hline Systolic pressure $(\mathrm{mmHg})$ & 265 & $115.3(16.0)$ & $82.0-181.0$ & 22 & $123.0(15.4)$ & $106.0-160.0$ & 0.030 \\
\hline Diastolic pressure $(\mathrm{mmHg})$ & 265 & $68.5(11.2)$ & $43.0-100.0$ & 22 & $71.4(8.2)$ & $60.0-91.0$ & 0.239 \\
\hline
\end{tabular}

Table 2. Comparisons of metabolic syndrome factors (waist circumference, glucose, triglycerides, HDC-cholesterol in blood, systolic pressure and diastolic pressure) between initial measurements and values obtained 2 years later

\begin{tabular}{|c|c|c|c|c|c|c|c|c|c|c|}
\hline \multirow{2}{*}{$\begin{array}{l}\text { Subjects with other than } \\
\text { abnormality detected }(n=185)\end{array}$} & \multicolumn{3}{|c|}{ Initial } & \multicolumn{3}{|c|}{2 years later } & \multicolumn{3}{|c|}{$\begin{array}{l}\text { Difference between second and initial } \\
\text { measurements }\end{array}$} & \multirow[t]{2}{*}{$p$ value } \\
\hline & mean SD & $\min$ & $-\max$ & mean SD & $\min$ & $-\quad \max$ & mean SD & $\min$ & $-\max$ & \\
\hline $\mathrm{BMI}\left(\mathrm{kg} / \mathrm{m}^{2}\right)$ & $20.9(2.9)$ & 16.2 & -45.1 & $21.0(3.0)$ & 15.2 & -46.7 & $0.03(0.8)$ & -4.3 & -2.6 & 0.598 \\
\hline Waist circumference $(\mathrm{cm})$ & $76.3(8.1)$ & 60.0 & - 119.0 & $77.2(8.6)$ & 60.5 & -128.5 & $0.85(4.0)$ & -12.0 & -14.2 & 0.161 \\
\hline Blood glucose $(\mathrm{mg} / \mathrm{dl})$ & $90.3(8.4)$ & 85.0 & -119.0 & $90.6(8.8)$ & 85.0 & -120.0 & $0.30(7.4)$ & -4.0 & -23.0 & 0.584 \\
\hline Triglycerides (mg/dl) & $79.8(42.9)$ & 27.0 & - 347.0 & $83.4(42.5)$ & 19.0 & - 269.0 & $3.60(36.6)$ & -204.0 & -140.0 & 0.182 \\
\hline HDL-cholesterol (mg/dl) & $78.3(16.3)$ & 44.0 & -125.0 & $78.4(16.6)$ & 42.0 & -129.0 & $0.07(9.6)$ & -24.0 & -35.0 & 0.921 \\
\hline Systolic pressure $(\mathrm{mmHg})$ & $115.8(16.5)$ & 82.0 & -181.0 & $113.8(14.5)$ & 85.0 & -166.0 & $-2.04(12.0)$ & -39.0 & --10.0 & 0.022 \\
\hline Diastolic pressure $(\mathrm{mmHa})$ & $68.8(11.3)$ & 43.0 & -97.0 & $67.9(11.0)$ & 44.0 & -111.0 & $-0.85(8.3)$ & -27.0 & -24.0 & 0.161 \\
\hline \multirow{2}{*}{$\begin{array}{l}\text { Subjects with abnormality } \\
\text { detected }(n=80)\end{array}$} & \multicolumn{3}{|c|}{ Initial } & \multicolumn{3}{|c|}{2 years later } & \multicolumn{3}{|c|}{$\begin{array}{l}\text { Difference between second and initial } \\
\text { measurements }\end{array}$} & \multirow[t]{2}{*}{$p$ value } \\
\hline & mean SD & $\min$ & $-\max$ & mean SD & $\min$ & $-\max$ & mean SD & $\min$ & $-\max$ & \\
\hline $\mathrm{BMI}\left(\mathrm{kg} / \mathrm{m}^{2}\right)$ & $21.7(3.7)$ & 16.5 & -35.3 & $21.7(3.7)$ & 17.2 & -34.6 & $0.07(1.1)$ & -4.8 & -3.1 & 0.588 \\
\hline Waist circumference $(\mathrm{cm})$ & $78.4(10.3)$ & 62.1 & -122.5 & $79.2(10.5)$ & 60.5 & -115.7 & $0.75(4.8)$ & -15.0 & -13.5 & 0.164 \\
\hline Blood glucose (mg/dl) & $89.3(15.5)$ & 82.0 & -171.0 & $89.2(12.9)$ & 82.0 & -153.0 & $-0.06(8.0)$ & -3.0 & -25.0 & 0.945 \\
\hline Triglycerides (mg/dl) & $82.5(59.8)$ & 27.0 & -428.0 & $83.1(66.9)$ & 32.0 & -585.0 & $0.59(33.2)$ & -115.0 & -157.0 & 0.875 \\
\hline HDL-cholesterol (mg/dl) & $73.4(14.7)$ & 33.0 & -130.0 & $75.5(15.7)$ & 36.0 & -125.0 & $2.05(8.3)$ & -26.0 & -21.0 & 0.030 \\
\hline Systolic pressure $(\mathrm{mmHg})$ & $114.2(14.8)$ & 86.0 & -163.0 & $114.8(15.5)$ & 92.0 & -173.0 & $0.63(11.2)$ & -24.0 & --6.3 & 0.618 \\
\hline Diastolic pressure $(\mathrm{mmHg})$ & $67.9(11.2)$ & 49.0 & -100.0 & 69.1 (12.3) & 47.0 & -112.0 & $1.20(8.8)$ & -29.0 & -24.0 & 0.226 \\
\hline \multirow[t]{2}{*}{ Total $(n=265)$} & \multicolumn{3}{|c|}{ Initial } & \multicolumn{3}{|c|}{2 years later } & \multicolumn{3}{|c|}{$\begin{array}{l}\text { Difference between second and initial } \\
\text { measurements }\end{array}$} & \multirow[t]{2}{*}{$p$ value } \\
\hline & mean SD & $\min$ & $-\max$ & mean SD & $\min$ & $-\quad \max$ & mean SD & $\min$ & $-\max$ & \\
\hline $\mathrm{BMI}\left(\mathrm{kg} / \mathrm{m}^{2}\right)$ & $21.2(3.2)$ & 16.2 & -45.1 & $21.2(3.2)$ & 15.2 & -46.7 & $0.04(0.9)$ & -4.8 & -3.1 & 0.449 \\
\hline Waist circumference $(\mathrm{cm})$ & $76.9(8.9)$ & 60.0 & -122.5 & $77.8(9.2)$ & 60.5 & -128.5 & $0.82(4.2)$ & -15.0 & -14.2 & 0.002 \\
\hline Blood glucose $(\mathrm{mg} / \mathrm{dl})$ & $90.0(11.0)$ & 66.0 & - 171.0 & $90.2(10.2)$ & 69.0 & - 153.0 & $0.19(7.6)$ & -32.0 & -4.0 & 0.685 \\
\hline Triglycerides (mg/dl) & $80.6(48.5)$ & 27.0 & -428.0 & $83.3(51.0)$ & 19.0 & -585.0 & $2.69(35.5)$ & -204.0 & -157.0 & 0.219 \\
\hline HDL-cholesterol (mg/dl) & $76.8(16.0)$ & 33.0 & -130.0 & $77.5(16.4)$ & 36.0 & -129.0 & $0.67(9.2)$ & -26.0 & -35.0 & 0.240 \\
\hline Systolic pressure $(\mathrm{mmHg})$ & $115.3(16.0)$ & 82.0 & -105.0 & $114.1(14.8)$ & 85.0 & -102.0 & $-1.23(11.8)$ & -39.0 & --9.0 & $<0.001$ \\
\hline Diastolic pressure $(\mathrm{mmHq})$ & $68.5(11.2)$ & 43.0 & -100.0 & $68.3(11.4)$ & 44.0 & -112.0 & $-0.23(8.5)$ & -29.0 & -24.0 & 0.653 \\
\hline
\end{tabular}

The results of binominal logistic regression analysis using grading of breast cancer screening findings as an objective variable are shown in Tables 3 and 4. Findings presented in Table 3 indicate the effects of metabolic syndrome factors noted at the initial assessment on development of mammary gland disease 2 years later. Using Model 1, waist circumference showed a significant association (odds ratio $=1.036, p$ $=0.045$ ), while that of HDL-cholesterol level was marginally significant (odds ratio $=0.982, p=0.064$ ). 
With Model 2, waist circumference again showed a significant association (odds ratio $=1.036, p=0.044$ ) and HDL-cholesterol level a marginally significant association (odds ratio $=0.982, p=0.064$ ). Table 4 shows the effects of changes in the examined metabolic syndrome factors at 2 years after the initial examination on development of mammary gland disease. With Model 3, which included waist circumference, glucose, triglyceride, and HDL-cholesterol levels in blood, and systolic pressure at the initial measurement, change in systolic pressure showed a marginally significant association (odds ratio $=1.020, p=0.085$ ). With Model 4 , which replaced systolic pressure with diastolic pressure, the marginally significant association of change in diastolic pressure was confirmed (odds ratio $=1.040, p=0.065$ ).

Table 3. Effects of metabolic factors at initial measurement on onset of mammary gland disease 2 years later

\begin{tabular}{cc|ccc}
\hline & & Odds ratio & $95 \% \mathrm{Cl}$ & p value \\
\hline \multirow{4}{*}{ Model1 } & Waist circumference(cm) & 1.036 & $1.001-1.073$ & 0.045 \\
& Blood glucose $(\mathrm{mg} / \mathrm{dl})$ & 0.987 & $0.960-1.016$ & 0.371 \\
& Triglycerides $(\mathrm{mg} / \mathrm{dl})$ & 0.999 & $0.992-1.005$ & 0.717 \\
& HDL-cholesterol $(\mathrm{mg} / \mathrm{dl})$ & 0.982 & $0.963-1.001$ & 0.064 \\
& Systolic pressure $(\mathrm{mmHg})$ & 0.997 & $0.977-1.017$ & 0.737 \\
\hline \multirow{4}{*}{ Model2 } & Waist circumference $(\mathrm{cm})$ & 1.036 & $1.001-1.072$ & 0.044 \\
& Blood glucose $(\mathrm{mg} / \mathrm{dl})$ & 0.987 & $0.959-1.015$ & 0.345 \\
& Triglycerides $(\mathrm{mg} / \mathrm{dl})$ & 0.999 & $0.992-1.005$ & 0.736 \\
& HDL-cholesterol $(\mathrm{mg} / \mathrm{dl})$ & 0.982 & $0.963-1.001$ & 0.064 \\
& Diastolic pressure $(\mathrm{mmHg})$ & 0.995 & $0.969-1.022$ & 0.729 \\
\hline \hline
\end{tabular}

Regulator factor

Model 1: Age at a initial measurement

Model 2: Age at a initial measurement 
Table 4. Effects of in metabolic syndrome factors over 2-year period on onset of mammary gland disease

\begin{tabular}{cc|ccc}
\hline \hline & & Odds ratio & $95 \% \mathrm{Cl}$ & $\mathrm{p}$ value \\
\hline \multirow{4}{*}{ Model3 } & Change in waist circumference $(\mathrm{cm})$ & 1.020 & $0.953-1.090$ & 0.571 \\
& Change in blood glucose $(\mathrm{mg} / \mathrm{dl})$ & 0.982 & $0.940-1.020$ & 0.401 \\
& Change in triglycerides $(\mathrm{mg} / \mathrm{dl})$ & 0.999 & $0.991-1.010$ & 0.830 \\
& Change in HDL-cholesterol $(\mathrm{mg} / \mathrm{dl})$ & 1.010 & $0.979-1.050$ & 0.445 \\
& Change in systolic pressure $(\mathrm{mmHg})$ & 1.020 & $0.997-1.050$ & 0.085 \\
\hline \multirow{4}{*}{ Model4 } & Change in waist circumference $(\mathrm{cm})$ & 1.010 & $0.948-1.090$ & 0.673 \\
& Change in blood glucose $(\mathrm{mg} / \mathrm{dl})$ & 0.978 & $0.937-1.020$ & 0.323 \\
& Change in triglycerides $(\mathrm{mg} / \mathrm{dl})$ & 0.999 & $0.990-1.010$ & 0.769 \\
& Change in HDL-cholesterol $(\mathrm{mg} / \mathrm{dl})$ & 1.010 & $0.974-1.040$ & 0.631 \\
& Change in diastolic pressure $(\mathrm{mmHg})$ & 1.040 & $0.998-1.080$ & 0.065 \\
\hline \hline
\end{tabular}

Regulator factors

Model 3: Age, waist circumference, blood glucose, triglycerides, HDL-cholesterol, and systolic pressure at initial measurement

Model 4: Age, waist circumference, blood glucose, triglycerides, HDL-cholesterol, and diastolic pressure at initial measurement

\section{Discussion}

The present results confirmed that waist circumference is a significant risk factor associated with development of mammary gland disease and the risk increased as waist circumference became larger. It has been speculated that hypertrophy and an increase in number of adipocytes due to obesity can have effects to facilitate adipokine secretion [8]. Also, Nagaoka et al. confirmed a significant correlation of waist circumference with both subcutaneous and visceral fat [9]. Based on those findings, it is considered that increased waist circumference in women might be induced by an increase of not only visceral but also subcutaneous fat. Additionally, it has been reported that accumulation of those types of fat is associated with hypertrophy and an increase in number of adipocytes, and that adipocyte accumulation has effects on adipokines $[10,11$.] Along with adipocyte accumulation, the secretion of leptin increases whereas that of adiponectin decreases, and those studies noted that an increased blood leptin level promotes vascularization and tumor proliferation. Furthermore, it has been shown that an increase in leptin level in blood induces production of vascular endothelial cell growth factor to promote endothelial cell growth in tumor vessels of the tumor, resulting in tumor enlargement, which has effects on the epithelium and interstitium of mammary gland tissue [12]. That study also reported that the incidence of breast cancer was increased in association with a decrease in blood adiponectin level and that nonuniform secretion of adipokine can be a cause of carcinogenesis by inducing enhanced insulin resistance. On the other hand, adipocytes produce estrogen by use of the male hormone androgen secreted from the adrenal cortex. Thus, it is considered that exposure to estrogen might have a close relationship with onset of breast cancer. Estrogen is known to be associated with development of mammary gland diseases including those with a benign nature [13]. Based on these findings, it is 
considered that hypertrophy and an increase in number of adipocytes associated with larger waist circumference may lead to increased risk for development of mammary gland disease.

Since the level of HDL-cholesterol is suggested to be a protective factor against mammary gland disease onset, it is possible that its anti-inflammatory effect and association with metabolic mechanism might be involved. Fiorenza et al. suggested that low HDL-cholesterol level, a risk factor for cardiovascular disease development, is related with occurrence of cancer in a variety of sites [14]. In the ARIC cohort study, it was reported that hypo-HDL-cholesterolemia $(50 \mathrm{mg} / \mathrm{dl})$ is related with onset of breast and prostate cancer [15]. Furberg et al. investigated the association between breast cancer and HDL-cholesterol level, and reported that the relative risk for cancer development was decreased to 0.73 in postmenopausal woman with an HDL-cholesterol level of $\geq 1.64 \mathrm{mmol} / \mathrm{L}(63.41 \mathrm{mg} / \mathrm{dL})$ as compared to those with a level $\leq$ $1.20 \mathrm{mmol} / \mathrm{L}(46.39 \mathrm{mg} / \mathrm{dL})$ [16]. In addition, that study found that the relative risk for cancer development was 0.68 in women with $\geq 1.64 \mathrm{mmol} / \mathrm{L}$ before menopause. Thus, high HDL-cholesterol level is associated with a decreased risk for breast cancer development, which was confirmed by the present results. Should HDL-cholesterol be involved in immune stimulation and inhibition of inflammatory response, it is possible that decreased HDL-cholesterol might inhibit malignant tumor development [17]. For mastopathy and fibroadenoma among benign mammary gland diseases, it is considered likely that inflammation is induced by a change in estrogen secretion on mammary gland epithelial cells [18]. Based on the present findings, it is possible that even benign mammary gland diseases are suppressed by the anti-inflammatory effect of HDL-cholesterol.

Since changes in systolic and diastolic blood pressure were suggested to be risk factors for the onset of mammary gland diseases, it is also considered that active oxygen induced by an increase in blood pressure might be involved. Hypertension is known to be a pathological condition of vascular endothelial disorder and one of its causes, and previous studies have shown that a variety of physiological active substances are produced and secreted in the vascular endothelium $[19,20]$. Once vascular endothelium becomes impaired, the balance of active oxygen is disrupted, resulting in breakdown of the vascular structure. Another study showed that oxidative reaction of active oxygen disturbed intravascular cells and the resultant oxidant stress elevated blood pressure [21]. It was also reported that blood pressure increase causes further oxidant stress [22], and that stress promotes proliferation of vascular smooth muscle, leading to arteriosclerosis and fluctuating blood pressure. Accordingly, it has been speculated that blood pressure elevation might result in development of hypertension [23]. Furthermore, it is known that DNA undergoes oxidative damage from oxidant stress [24,25], while others have shown that tetradecanoyl phorbol (TPA), a carcinogen formed by DNA damage, induces activation of breast cancer cells [26-28]. Therefore, it is likely that an increased concentration of active oxygen might impair mammary gland cells, leading to onset of mammary gland disease.

In the present study, results of breast cancer screening leading to a mammography grade of 3 or higher were used for analysis. Subjects graded as category 3 or higher were subjected to detailed examinations at Atami Hospital Department of Surgery, International University of Health and Welfare, Japan, which showed that approximately $12 \%$ of the category 3 subjects and approximately $55.5 \%$ of those classified 
as category 4 had a malignant tumor, while the ratio of benign tumors was $60.5 \%$ for category 3 and $30 \%$ for category 4 . Those results showed that category 3 cases are a mixture of benign and malignant tumors [29]. Breast cancer most often develops from epithelial cells of the mammary gland according to the following tumorigenic process. A multifocal genetic mutation occurs in normal epithelial cells, making them precancer cells. With excessive proliferation of precancer cells, a benign tumor is formed. Then, with further genetic mutation activity in the benign tumor, a metastatic malignant tumor is formed as a result of tissue infiltration. When the Ras gene is activated simultaneously with mitochondrial dysfunction in some of the cells of a benign tumor, the pathway of communication that senses intracellular stress is activated to release 2 types of protein outside the cells. Those released proteins are inflammatory cytokine and cell growth factor, which stimulate other cells in the benign tumor to increase cell proliferation, tissue infiltration, and metastasis, resulting in malignant tumorigenesis [30].

The present study was not designed to clarify the mechanism of tumorigenesis from a benign to malignant tumor. However, based on our understanding that a benign tumor has the possibility of malignant alteration, we consider that examination of routine screening data of metabolic syndrome factors, such as waist circumference, blood pressure, and HDL-cholesterol level, in subjects with mammary gland disease graded as category 3 or higher might lead to effective treatments for control of breast cancer onset.

In an effort to reduce mortality related to breast cancer, the Ministry of Health, Labor and Welfare of Japan, for the purpose of early detection and treatment, began advocating screening by mammography combined with visual inspection and palpation for women aged 50 years and older in 2000, and then lowered the age to 40 years or older in 2004. In the present study as well, the results of breast cancer screening by mammography were used. The effect of such screening for decreasing mortality was initially examined in the United States by a randomized-controlled trial conducted in 1963, with several related studies subsequently presented, mainly using subjects in Western countries [31-35]. As a result, it has been noted that 10 years after beginning mammography screening the mortality rate ranged from 17-30\% among women over 50 years old, indicating a significantly good effect [36] and showing the usefulness of such screening. In comparison to an examination limited to visual inspection and palpation, those combined with mammography has tripled the detection rate. Notably, the probability of detection is high among subjects with early stage breast cancer. However, in the present study, screening was performed only using mammography, without breast ultrasound or tomosynthesis.

It has been reported that the breast cancer detection rate was higher when ultrasonography was combined with mammography as compared to the latter alone in Japanese women, who frequently have dense breast tissue [37]. Previous reports have noted that combined use of mammography and ultrasound for screening was helpful to improve the rate of cancer detection [38-41]. Regarding tomosynthesis, a clinical trial compared screening by mammography combined with tomosynthesis with that performed by conventional 2D mammography found that the breast cancer detection rate was increased by $27 \%$ with that combination and the ratio of subjects determined to require a more detailed examination was decreased by $15 \%$ [42]. Accordingly, it is considered necessary to examine the results of 
screening in combination with findings obtained with ultrasound and tomosynthesis as auxiliary techniques.

For the present study, 2 accredited physicians provided the mammogram interpretations, thus internal validity was considered high even though screening was performed only with mammography. We did not examine the effects of menopause on mammary gland disease, as that was not a factor determined in the present cohort. Another potential confounding factor is smoking, though that also was not considered as a factor in this study. Cox DG et al. performed unconditional logistic regression analysis and found that the risk for breast cancer was higher in women who had smoked for 20 years or more as compared to those without that habit (odds ratio $=1.28,95 \%$ confidence interval $=1.17-1.39$ ) [43]. Also, Hanaoka $T$ et al. evaluated results of epidemiological studies with women in Japan as subjects, including 3 cohort and 8 case-control studies, and noted that a smoking habit was likely to increase the risk for breast cancer, thus smoking cannot be denied as a possible confounder [44]. In a future study, we intend to verify that by including smoking habit in the questionnaire.

The physical constitution of the present subjects was similar to that of subjects of the same age in another survey conducted in Japan [45]. Furthermore, the measurements were approximately the same as those excluded from analysis. Accordingly, the results of the present study, at least from the viewpoint of physical constitution, are considered to be valid for young women in Japan. Also, since the subjects were not inpatients at a medical institution or nursing-care facility, but rather voluntary participants of a health checkup, it is likely that the population was comprised of healthy or highly health-conscious individuals. A significant difference in regard to systolic pressure was noted between the analyzed subjects and those excluded. Since the mean age of those excluded was higher, it is likely that age was involved as a factor and possible that subjects with higher blood pressure levels were excluded. The systolic pressure value of those excluded was $123.05 \mathrm{mmHg}$, while the standard value in diagnostic criteria for metabolic syndrome is $130 \mathrm{mmHg}$ or lower. Whether systolic pressure had effects on the present results is unknown, though that at the initial measurement was not associated with risk determination. Accordingly, we think that systolic pressure in those excluded from analysis did not exert significant effects on the present results. When we used the data $(n=265)$ of this study to conduct a cross-sectional survey of BMI and mammary gland disease, the odds ratio of BMl at the onset of mammary gland disease was $1.08(95 \% \mathrm{Cl}$ : $0.998-$ 1.18 , p value: 0.056$)$.

\section{Conclusion}

We performed a longitudinal study of the association between metabolic syndrome factors (waist circumference, glucose, triglyceride, and HDL-cholesterol levels in blood, blood pressure) and development of mammary gland disease including breast cancer using routine test data from 265 subjects collected during breast cancer screening by mammography conducted twice in a 2-year period from 2010 to 2013. A significant association of waist circumference with mammary gland disease was confirmed, as greater waist circumference increased the risk of mammary gland disease development. Furthermore, a marginally significant association with HDL-cholesterol level at the initial examination 
was confirmed as a protective factor, with a higher level found to the lower the risk. Changes in systolic and diastolic pressure between mammography examinations also had a marginally significant association and it is likely that greater increases in blood pressure over the 2-year period increased the risk of mammary disease. Findings of the present longitudinal study of the association between metabolic syndrome factors and risk for development of mammary gland diseases should be useful for early detection and treatment of breast cancer, as well as increasing physician awareness.

\section{Declarations}

\section{Ethics approval and consent to participate}

This study was conducted in accordance with the Declaration of Helsinki and performed after receiving approval from the Hiroshima Welfare Ren Yoshida General Hospital Ethics Committee (approval number 201607). Informed consent was obtained from all individual participants included in the study. Each was given a full explanation of the study content and methods in advance, and their written consent was obtained.

\section{Consent for publication}

All respondents provided consent to publish before completing the questionnaires.

\section{Competing interests}

The authors have no competing interests to declare in regard to this study.

\section{Availability of data and material}

Data associated with this study cannot be shared publicly because of ethical or legal restrictions for public deposition owing to inclusion of sensitive information from human participants, which is based on regulations for ethical guidelines in Japan and the ethical review board of the Yoshida General Hospital Ethics Committee. Obtained data and materials were used only for the present study, and are available only to researchers who participated in the study project.

\section{Conflicts of interest}

K.N. and M.Y. are employees of Preventive Medicine Promotion Research Center, which provided funds for this study. Those authors had a role in the design of the study and discussed obtained data. No other authors have conflicts of interest to declare. 


\section{Authors' contributions}

T.I. developed the study protocol, and K.N., S.S., and M.Y. obtained measurements and interview results. All authors contributed to writing the manuscript and T.I. revised the text. Each provided critical contributions to interpretation of the data and associated comments. The final version was approved by all of the authors.

\section{Financing}

This study received financial support from the Preventive Medicine Promotion Research Center.

\section{References}

1. Andrew GR, Margaret T, Matthias E, Richard FH, Marcel Z. Body-mass index and incidence of cancer: a systematic review and meta-analysis of prospective observational studies. Lancet. 2008;371(9612):569-78. https://doi.org/10.1016/S0140-6736(08)60269-X.

2. Yoo K, Tajima K, Park S, Kang D, Kim S, Hirose K, et al. Postmenopausal obesity as a breast cancer risk factor according to estrogen and progesterone receptor status(Japan). Cancer Lett. 2001;167囚1 邓:57-63. https://doi.org/10.1016/S0304-3835(01)00463-3.

3. Hirose K, Tajima K, Hamajima N, Kuroishi T, Kuzuya K, Miura S, et al. Comparative case-referent study of risk factors among hormone-related female cancers in Japan. Jpn J Cancer Res. 1999; 90(3): 255-61. https: //doi.org/10.1111/j.1349-7006.1999.tb00741.x.

4. Tung HT, Tsukuma H, Tanaka H, Kinoshita N, Koyama Y, Ajiki W, et al. Risk factors for breast cancer in Japan, with special attention to anthropometric measurements and reproductive history. Jpn J Clin Oncol. 1999; 29(3)137 - 46. https://doi.org/10.1093/jjc-o/29.3.137.

5. Hu YH, Nagata C, Shimizu H, Kaneda N, Kashiki Y. Association of body mass index, physical activity, and reproductive histories with breast cancer: a case-control study in Gifu, Japan. Breast Cancer Res Treat. 1997;43(1):65-72. https://doi.org/10.1023/A:100574582-4388.

6. Journal of the Japanese Society for Food Science and Technology. Nippon shokuhin kagaku kogaku kaishi.2010; 57(7): 319. https: //doi.org/10.3136/nskkk.46.428 (in Japanese).

7. Antuna-Puente B, Feve B, Fellahi S, Bastard JP. Adipokines: The missing link between insulin resistance and obesity. Diabetes Metab. 2008; 34: 2-11. https: //doi.org/.10.1016/j.diabet.2007.09.004.

8. Miller WM, Nori-Janosz KE, Lillystone M, Jose Y, Peter A, Cullough. Obesity and lipids. Curr Cardiol Rep 7, 465-470 (2005). https: //doi.org/10.1007/s11886-005-0065-8.

9. Nagaoka K, Kagiono M, Fujita K, Wada A, Aatsui H, Ohashi M, et al. Comparison of Metabolic Syndrome Patients in Terms of BMI and Subcutaneous and Visceral Fat Obesity. Japan Society of Ningen Dock. 2010;20:486-93. https: //doi.org/10.11320/ningendock.25.486 (in Japanese). 
10. Cirillo D, Rachiglio AM, Montagna RL, Giordano A, Normanno N. Leptin signaling in breast cancer. J Cell Biochem. 2008; 105(4): 956-64. https://doi.org/ 10.1002/jcb.21911.

11. Gale Newman,Ruben Rene Gonzalez-Perez. Leptin-cytokine crosstalk in breast cancer. Mol Cell Endocrinol.2014; 382(1): https: //doi.org/ 10.1016/j.mce.2013.03.025.

12. Miyoshi Y, Funahashi T, Kihara S, Taguchi T, Tamaki Y, Matsuzawa Y, et al. Association of serum adiponectin levels with breast cancer risk. Clin Canser Res. 2003;9:5699-704. DOI:Published November 2003.

13. Sasaki Y, Miki Y, Hirakawa H, Onodera Y, Takagi K, Akahira J, et al. Immunolocalization of estrogenproducing and metabolizing enzymes in benign breast disease: Comparison with normal breast and breast carcinoma.Cnacer Scince.2010. https://doi.org/10.1111/j.1349-7006.2010.01673.x.

14. Fiorenza AM, Branchi A, Sommariva D. Serum lipoprotein profile in patients with cancer. $A$ comparison with non-cancer subjects. Int J Clin Lab Res. 2000;30(3):141-5. https://doi.org/10.1007/s005990070013.

15. Kucharska-Newton AM, Rosamond WD, Mink PJ, Alberg AJ, Shahar E. Folsom AR.HDL-cholesterol and incidence of breast cancer in the ARIC cohort study.Ann Epidemiol 2008; 18(9): 671-7. https://doi.org/ 10.1016/j.annepidem.2008.06.006.

16. Furberg AS, Veieroad MB, Wilsgaard T, Bernstein L, Thune I. Serum high density lipoprotein cholesterol, Metabolic profile, and Breast cancer risk. J Natl Cancer Inst. 2004;96:1152-60. https://doi.org/ 10.1093/jnci/djh216.

17. Shor R, Waunstein J, Oz D, Boaz M, Matas Z, Fux A, Halabe A. Low HDL levels and the risk of death, sepsis and malignancy. Clin Res Cardiol. 2008;97:227-33. https://doi.org/10.1007/s00392-0070611-z.

18. Seki R. HISTOLOGICAL STUDIES ON THE MAMMARY GLAND-Comparison in Mammary glands of autopsy, biopsy, and amputation cases. Department of Surgery, Showa Medical School. 1961; 20(10): 1392-1411.(in Japanese).

19. Vanhoutte PM. Endothelium and control of vascular function. Hypertension. 1989; 13: 658-67. https://doi.org/ 10.1161/01.HYP.13.6.658.

20. Lucher TF. Imbalance of endothelium-derived relaxing and contracting factors. Am J Hypertens. 1990;3:317-30. https://doi.org/10.1093/ajh/3.4.317.

21. Hirata Y, Satonaka H. Hypertension and Oxidative Stress. Department of Cardiovascular Medicine. University of Tokyo JMA Journal. 2001;44(12):540-5.

22. Kodlipet D, Michael EW. Vascular Endothelial Function and Hypertension: Insights and Directions. Curr Hypertens Rep. 2010;12(6):448-55. https://doi.org/10.1007/s11906-010-0150-2.

23. Ward NC, Croft KD. Clin Exp Pharmacol Physiol. 2006;33(9):872-6. https://doi.org/10.1111/j.14401681.2006.04457.x.

24. Cerutti PA. Prooxidant states and tumor promotion. Science. 1985;227(4685):375-81. https://doi.org/10.1126/science.2981433. 
25. Ledur PF, Karmirian K, Pedrosa CDSG, Souza LRQ, Assis-de-Lemos G, Martins TM,et al. Zika virus infection leads to mitochondrial failure, oxidative stress and DNA damage in human iPSC-derived astrocytes. Sci Rep. 2020 Jan 27; 10(1): 1218. https://doi.org/ 10.10-38/s41598-020-57914-x.

26. Zajac-Kaye M, Paul OP. DNAase I encapsulated in liposomes can induce neoplastic transformation of syrian hamster embryo cells. in cultureCell. 1984;39:427-37. ãष区 https://doi.org/10.1016/00928674(84)90450-1.

27. Nagata C, Tagashira Y, Kodama M, loki Y, Oboshi S. Effect of hydrogen peroxide, Fenton's reagent, and iron ions on the carcinogenicity of 3, 4-benzopyrene. Gan. 1973;64(3):277-85. https://doi.org/10.20772/cancersci1959.64.3_277.

28. Tao R, Coleman MC, Pennington S, Ozden D, Park O, Jiang SH. H et al. Sirt3-Mediated Deacetylation of Evolutionarily Conserved Lysine 122 Regulates MnSOD Activity in Response to Stress. Mol Cell. 2010;40(6):893-904. https://doi.org/10.1016/j.molc-el.2010.12.013.

29. Inari H, Uesugi K, Hatori S, Kawamoto M, Goto N, Iwasaki H, et al. The Examination of Category 3,4, and 5 Mammography Case. Japan Association of Breast Cancer Screening. 2011;20(2):135-8. https://doi.org/10.3804/jjabcs.20.135 (in Japanese).

30. Ohsawa S, Sato Y, Enomoto M, Nakamura M, Betsumiya A, Igaki T. Mitochondrial defect drives nonautonomous tumour progression through Hippo signalling in Drosophila. Nature. 2012;490:547-51. https://doi.org/10.1038/nature11452.

31. Shapiro S, Venet W, Strax P, Venet L, Roeser R. Ten-to fourteen-year effect of screening on breast cancer mortality. J Natl Cancer Inst. 1982;69(2):349-55. https://doi.or-g/10.1093/jnci/69.2.349.

32. Tabár L, Fagerberg CJ, Gad A, Baldetorp L, Holmberg LH, Gröntoft O, et al. Reduction in mortality from breast cancer after mass screening with mammography. Randomised trial from the Breast Cancer Screening Working Group of the Swedish National Board of Health and Welfare. Lancet. 1985;1(8433):829-32. https://doi.org/10.1016/s01406736(85)922-04-4.

33. Ingvar A, Kunt A, Lars J, Torsten L, Karin L, Folke L, et al. Mammographic screening and mortality from breast cancer: the Malmö mammographic screening trial. BMJ. 1988;297(6654):943-8. https://doi.org/10.1136/bmj.297.6654.943.

34. Nyström L, Andersson I, Bjurstam N, Frisell J, Nordenskjöld B, Rutqvist LE. Long-term effects of mammography screening: updated overview of the Swedish randomised trials. Lancet. 2002;359(9310):909-19. https://doi.org/10.1016/S0140-6736(02)08020-0.

35. Alexander FE, Anderson TJ, Brown HK, Forrest AP, Hepburn W, Kirkpatrick AE,et al. 14 years of followup from the Edinburgh randomised trial of breast-cancer screening. Lancet. 1999;353(9168):19038. https://doi.org/10.1016/S0140-6736(98)07413-3.

36. Smith RA, Duffy SW, Gabe R, Tabar L, Yen AM, Chen TH. The randomized trials of breast cancer screening: what have we learned? Radiol Clin North Am. 2004;42(5):793-806. https://doi.org/10.1016/j.rcl.2004.06.014.

37. Leong LC, Gogna A, Pant R, Ng FC, Sim LS. Supplementary breast ultrasound screening in Asian women with negative but dense mammograms-a pilot study. Ann Acad Med Singapore. 
2012;41(10):432-9.

38. Nothacker M, Duda V, Hahn M, Warm M, Degenhardt F, Madjar H, et al. Early detection of breast cancer: benefits and risks of supplemental breast ultrasound in asymptomatic women with mammographically dense breast tissue. A systematic review. BMC Cancer. 2009;9:335. https://doi.org/10.1186/1471-2407-9-335.

39. Weigert J, Steenbergen S. The connecticut experiment: the role of ultrasound in the screening of women with dense breasts. Breast J. 2012;18(6):517-22. https://doi.o-rg/10.1111/tbj.12003.

40. Honjo S, Ando J, Tsukioka T, Morikubo H, Ichimura M, Sunagawa M, et al. Relative and combined performance of mammography and ultrasonography for breast cancer screening in the general population: a pilot study in Tochigi Prefecture, Japan. Jpn J Clin Oncol. 2007;37(9):715-20. https://doi.org/10.1093/jjco/hym090.

41. Uchida K, Yamashita A, Kawase K, Kamiya K. Screening ultrasonography revealed $15 \%$ of mammographically occult breast cancers. Breast Cancer. 2008;5(2):165-8. https://doi.org/10.1007/s12282-007-0024-x.

42. Skaane P, Bandos Al, Gullien R, Eben EB, Ekseth U, Haakenaasen U, et al. Comparison of digital mammography alone and digital mammography plus tomosynthesis in a population-based screening program. Radiology. 2013;267(1):47-56. https://doi.org/10.1148/radio-l.12121373.

43. Cox DG, Dostal L, Hunter DJ, Le Marchand L, Hoover R, Ziegler RG, et al. N-acetyltransferase 2 polymorphisms, tobacco smoking, and breast cancer risk in the breast and prostate cancer cohort consortium. Am J Epidemiol. 2011;174(11):1316-22. https://do-i.org/10.1093/aje/kwr257.

44. Hanaoka T, Yamamoto S, Sobue T, Sasaki S, Tsugane S. Japan Public Health Center-Based Prospective Study on Cancer and Cardiovascular Disease Study Group. Active and passive smoking and breast cancer risk in middle-aged Japanese women. Int J Cancer. 2005;20:317-22. https://doi.org/10.1002/ijc.20709.

45. Health and Welfare Statistics Association. Journal of Health and Welfare Statistics. 57. Tokyo: Kosaido Co. Ltd; 2010. (9 .460 (in Japanese).

\section{Figures}




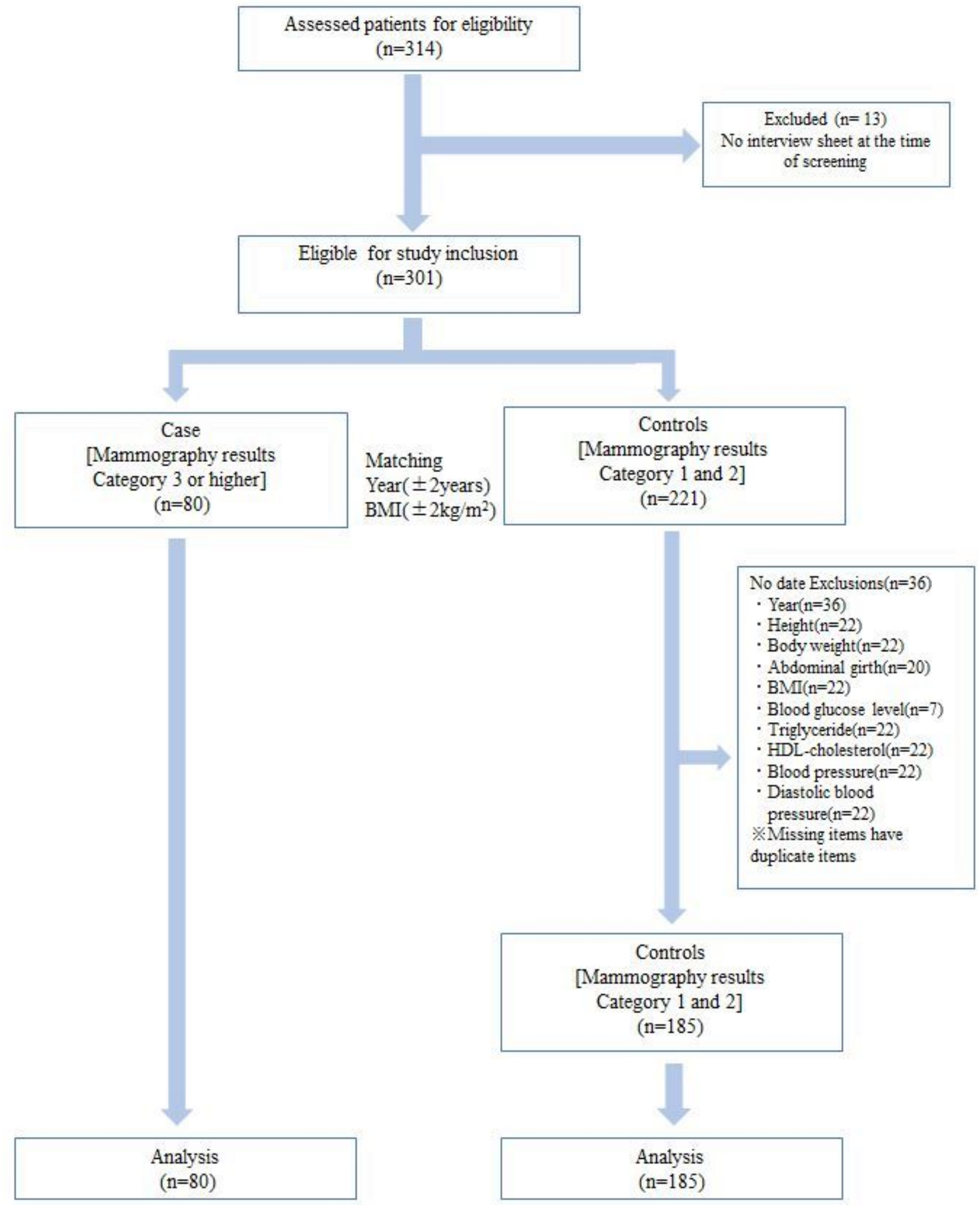

\section{Figure 1}

Flow diagram of this case-control study 